\title{
Design of a Television Viewer Safe Distance Control Device for Children Ages 5 to 10 Years Using Arduino Uno with Motion Sensor and Proximity Sensor
}

\section{Rancang Bangun Alat Pengatur Jarak Aman Pemirsa Televisi Untuk Anak Usia 5 Sampai 10 Tahun Menggunakan Arduino Uno Dengan Sensor Gerak Dan Sensor Jarak}

\author{
Imam Faizal', Samsul Arifin ${ }^{2}$ \\ \{imamfaizal17@gmail.com $\left.{ }^{1}, \underline{\text { s4ms.s0ul@gmail.com }}{ }^{2}\right\}$
}

Program Studi Sistem Komputer, Fakultas Teknologi \& Desain, Institut Teknologi \& Bisnis ASIA Malang

\begin{abstract}
When a child is 5 to 10 years old, it is very vulnerable to experience impaired health. One of them is vision. Vision is the main source that is very useful for life. A mother is worried when her children are constantly watching television. The anxiety will increase when children watch their favorite shows on television is very closely distance. From the description of the problem above, the writer found an idea to make a tool that can remind young children to maintain their visibility while watching television. The tool uses an Arduino Uno microcontroller coupled with a distance sensor and a motion sensor. When the sensor detects humans are closed to the television, then the tool will give a warning through the speaker in the form of sound. From the results of research when the sensor detects the distance between humans and the television is too close, the device will warn by making noise from the speakers. After 20 trials, data was obtained that 17 times the device is successfully detected movement via sensor and could give a warning to television viewers. Hope with the creation of a television viewers safe space can help parents to reduce anxiety when children watch television
\end{abstract}

Keywords - Motion Sensor; Distance Sensor; Speaker; Television; Arduino Uno R3

\begin{abstract}
Abstrak. Pada saat seorang anak berusia 5 sampai 10 tahun, sangatlah rawan kesehatan terganggu. Salah satunya adalah penglihatan. Penglihatan adalah sumber utama yang sangat berguna untuk kehidupan. Seorang ibu cemas ketika anak-anaknya tersebut terus menerus menonton tayangan di televisi. Rasa cemas tersebut akan bertambah ketika anak-anak menonton tayangan favoritnya di televisi dengan sangat dekat. Dari gambaran masalah diatas, penulis menemukan ide untuk membuat alat yang bias mengingatkan anak-anak kecil agar menjaga jarak pandang saat menonton televisi. Alat tersebut menggunakan microcontroller Arduino Uno ditambah dengan sensor jarak dan sensor gerakan, ketika sensor mendeteksi manusia berjarak dekat dengan televisi, maka alat akan memberikan peringatan lewat speaker berupa suara. Dari hasil penelitian ketika sensor mendeteksi jarak antara manusia dan televisi terlalu dekat, maka alat akan memperingatkan dengan mengeluarkan bunyi dari speaker. Setelah dilakukan 20 kali percobaan, didapatkan data bahwa 17 kali alat berhasil mendeteksi pergerakan melalui sensor dan dapat memberi peringatan untuk pemirsa televisi. Harapan dengan terciptanya alat pengatur jarak aman pemirsa televisi ini mampu membantu orangtua mengurangi rasa cemas ketika anak-anak menonton televisi.
\end{abstract}

Kata Kunci - Sensor Gerak; Sensor Jarak; Speaker; Televisi; Arduino Uno R3

\section{Pendahuluan}

Menonton televisi dalam jarak dekat dapat menyebabkan mata minus, jarak pandang yang terlalu dekat saat menyaksikan siaran di televisi dapat memicu terjadinya sindrom mata lelah. Sindrom mata lelah ditunjukkan dengan gejala mata perih, berair dan sakit kepala. Walau tidak berbahaya dan dapat teratasi dengan berhenti memandang layar televisi, komputer atau produk elektronik lainnya, keluhan ini tak boleh diabaikan. Memang tidak berdampak saat masih anak-anak. Namun, dampaknya akan terasa saat dewasa nanti, terkait dengan penyakit stroke mata.

Pada penelitian sebelumnya yang dilakukan oleh Fakhrunnisa [1] sistem dilengkapi dengan sensor ultrasonic untuk mendeteksi penonton tv, kemudian pada penelitian Purnomo dkk [2] sistem juga sama menggunakan sensor ultrasonik. Begitupun dengan penelitian yang dilakukan oleh Novianto [3] menggunakan sensor ultrasonic sebagai pengukur jarak akan tetapi alat belum bisa mematikan televisi. Penelitian yang dilakukan oleh Nasyam [4] belum menggunakan pengaturan untuk jarak yang dikehendaki apabila ada perubahan pada layar televisi. Penelitian selanjutnya oleh Sadi [5] menggunakan sensor PIR untuk mendeteksi adanya manusia dan sensor ultrasonik untuk mendeteksi jarak tetapi belum menggunakan keypad. Penelitian yang dilakukan oleh Setyanto [6] menggunakan 
arduino uno sebagai pengendali tetapi juga belum menggunakan keypad. Kemudian pada penelitian Widodo [7] menggunakan ATMega 8535 tetapi belum menggunakan keypad.

Pada penelitian ini akan dilakukan pengembangan dengan penambahan keypad. Keypad ini berfungsi untuk mengatur jarak yang dijadikan sebagai pengingat buzzer. Sebuah Sistem akan terasa saat dewasa nanti, terkait dengan penyakit stroke mata sebuah sistem yang menggunakan keypad nantinya [8]. Keypad merupakan antarmuka antara komunikasi perangkat elektronik dengan manusia yang disebut dengan istilah HMI (Human Machine Interface) [9] [10]. Keypad tersusun atas 16 buah push button yang dirangkai dengan konfigurasi dalam bentuk matrix, sehingga memiliki index baris dan kolom sehingga pin input ke Arduino dapat dikurangi.

\section{Hasil Dan Pembahasan}

\section{A. Perancangan Alat}

Pada proses perancangan alat pengatur jarak aman pandang otomatis ini akan dibahas mengenai hal yaitu perancangan sistem yang meliputi perancangan hardware, perancangan software, perancangan mekanik serta rangkaian keseluruhan sistem, dimana semua perancangan sistem ini akan saling menunjang untuk proses pengoperasian alat ini.

\section{- Perancangan Sistem}

Pada perancangan alat ini akan dibuat alur system dimana jika sensor PIR HC-SR501 mendeteksi adanya pergerakan manusia maka akan mengirim data pada Arduino untuk membaca jarak pada sensor jarak HC-SR04 dan jika keberadaan manusia kurang dari 3 meter dari televisi maka alat akan berbunyi berupa beep peringatan hingga jarak terhadap televisi sesuai yang diinginkan. Kemudian apabila tiga kali peringatan masih tetap berada di depan televisi terlalu dekat, maka sistem akan otomatis mematikan arus listrik dari televisi sehingga televisi akan seketika mati. Kemudian, televisi bisa dihidupkan kembali secara manual.

\section{- Perancangan Software}

Perangkat lunak pada perancangan system dibangun menggunakan Arduino IDE (Integrated Development Environment) dengan Bahasa C yang mirip dengan C++ dan Java. Untuk mengakses bagianbagian dari system dapat diatur di dalam Arduino IDE.

\section{- Perancangan Mekanik}

Alat pengatur jarak aman otomatis ini dirancang dengan tiga bagian dengan ukuran (Panjang $\mathrm{x}$ Lebar $\mathrm{x}$ Tinggi) dengan 1 buah box yang berfungsi untuk meletakkan Arduino, sensor jarak, sensor gerak, DFplayer module, dan speaker. Bagian tersebut dapat diuraikan sebagai berikut:

1. Bagian pertama adalah tampak samping, depan, dan belakang

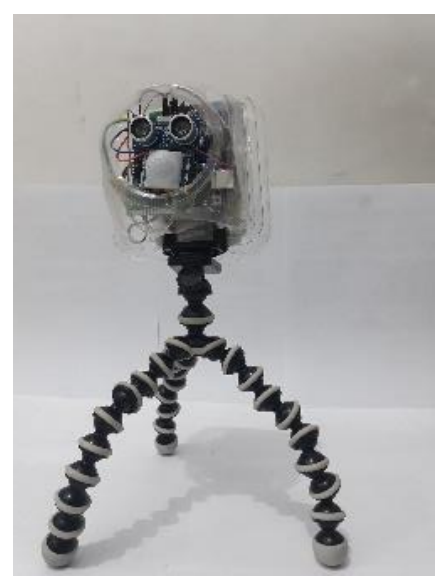

Gambar 1. Alat tampak depan 
Procedia of Engineering and Life Science Vol. 1. No. 2 Juni 2021

Seminar Nasional \& Call Paper Fakultas Sains dan Teknologi (SENASAINS 2nd)

Universitas Muhammadiyah Sidoarjo

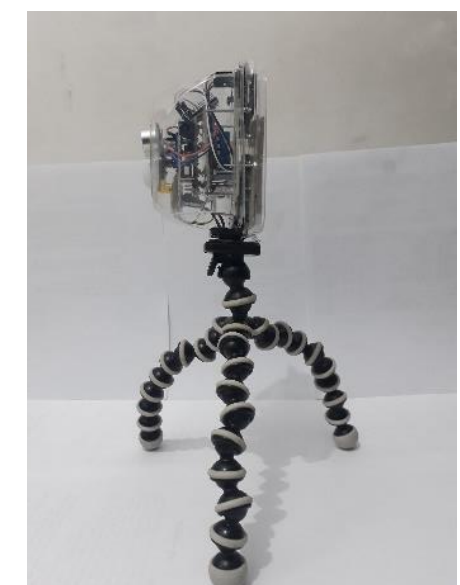

Gambar 2. Alat tampak samping

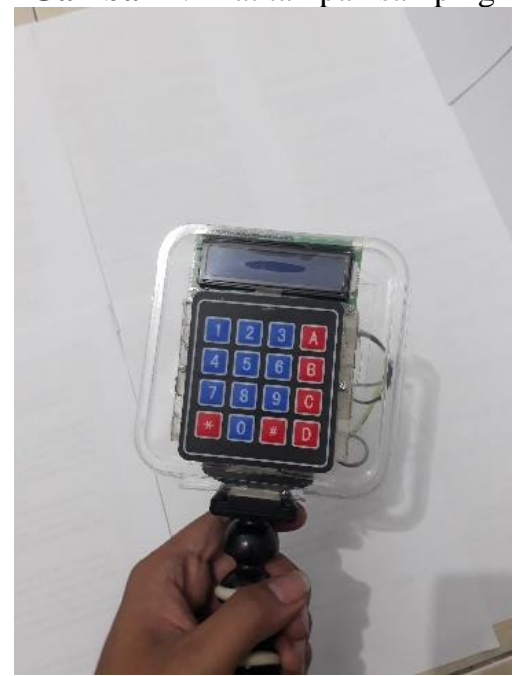

Gambar 3. Alat tampak belakang

2. Bagian kedua adalah gambar keseluruhan dan diagonal.

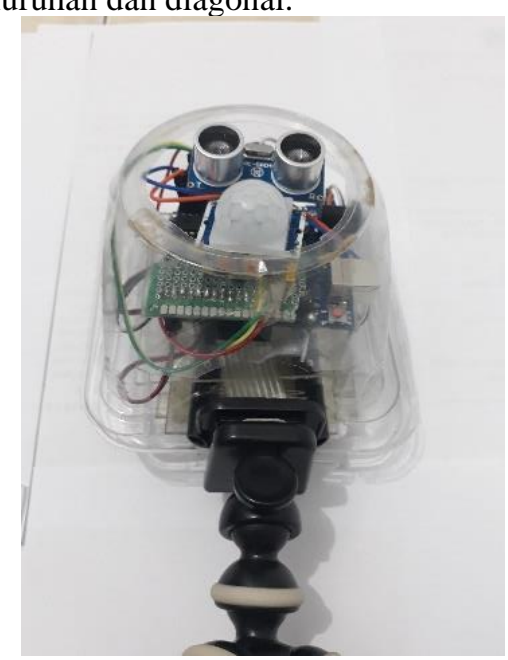

Gambar 4. Alat tampak keseluruhan 


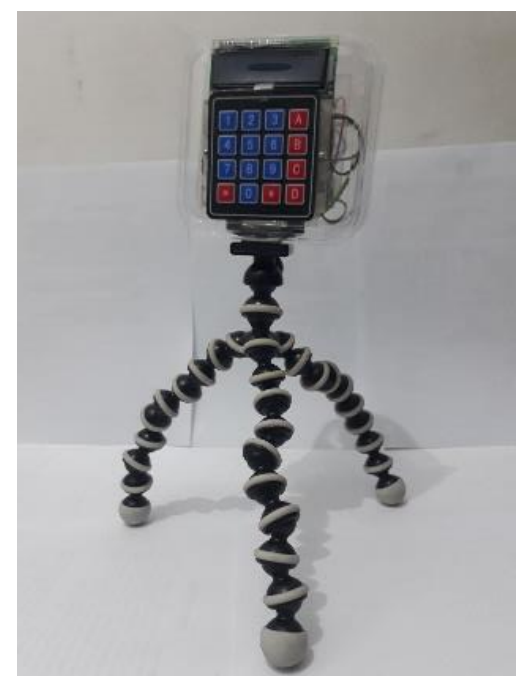

Gambar 5. Alat tampak diagonal

3. Bagian ketiga adalah bagian dalam alat.

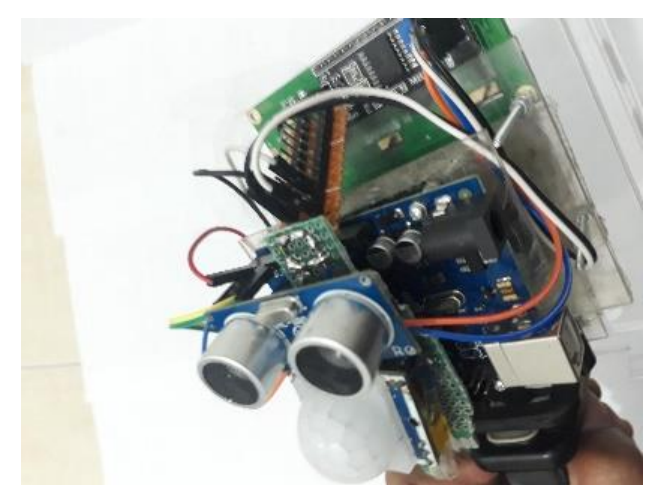

Gambar 6. Bagian dalam alat

\section{B. Pengujian Alat}

Dalam pengujian ini dilakukan untuk mengetahui kinerja dari sistem dan untuk mengetahui apakah sudah sesuai dengan perencanaan atau belum. Pengujian ini dilakukan secara terpisah, dan kemudian dilakukan ke dalam system yang telah terintregasi. Untuk itu dilakukan pengujian yang meliputi:

1. Pengujian Sistem Arduino Uno R3

2. Pengujian Sensor Gerak HC-SR501

3. Pengujian Sensor Jarak HC-SR04

4. Pengujian LCD 16x2

5. Pengujian Keypad $4 \times 4$

6. Pengujian Module Relay

7. Spesifikasi Keseluruhan Alat.

\section{KESIMPULAN}

Berdasarkan analisa hasil perancangan tersebut, maka dapat kesimpulan sebagai berikut:

1. Sensor gerak dapat mendeteksi manusia dari gerakan yang terjadi.

2. Sensor pengukur jarak dapat mengetahui jarak ketika ada manusia yang mendekat dengan televisi.

3. Ketika ada anak kecil sangat dekat dengan televisi maka alat mengeluarkan peringatan hingga 3 kali.

4. Relay dapat memutus arus pada stopkontak.

5. Speaker dapat bekerja dengan baik. 
Procedia of Engineering and Life Science Vol. 1. No. 2 Juni 2021

Seminar Nasional \& Call Paper Fakultas Sains dan Teknologi (SENASAINS 2nd)

Universitas Muhammadiyah Sidoarjo

Dalam penelitian ini, sistem yang dibuat masih terdapat kelemahan, sehingga dalam hal ini diharapkan alat ditambahkan sensor pendeteksi usia dan desain mekanik masih kasar, maka perlu dikembangkan lagi agar tampilan lebih praktis, kuat, dan efisien.

\section{REFERENSI}

[1] Fakhrunnisa, "Perancangan Alat Pendeteksi Jarak Nyaman Menonton Televisi Berbasis Mikrokontroller ATMEGA 8535," Universitas Sumatra Utara, Medan, 2017.

[2] A. Purnomo, C. E. Widodo and dkk, "Smart Sensor Television: Alat Pendeteksi Jarak Pandang Televisi Otomatis Sebagai Upaya Menjaga Kesehatan Mata," [Online].

[3] C. Novianto, "Pemantau Jarak Tonton Televisi," Program Studi Teknik Elektro Universitas Sanata Dharma, Yogyakarta, 2010.

[4] R. Nasyam, "Media Deteksi Pengukuran Jarak Aman Menonton Televisi Menggunakan Arduino," Universitas Mercu Buana Jatisampurna, Bekasi, 2017.

[5] S. Sadi, "Aplikasi Pendeteksi Manusia Pada Televisi Berbasis Mikrokontroler Atmega8535," Jurnal Teknik, vol. V, no. 2, 2016.

[6] D. Setyanto, "Kendali On/Off Televisi Menggunakan Sensor Jarak Berbasis Arduino Uno," Universitas Gadjah Mada, Yogyakarta, 2015.

[7] S. Widodo, R. Laipaka and N. E. Putriani, "Rancang Bangun Alat Pendeteksi Jarak Aman Menonton TV Menggunakan Mikrokontroler ATmega 8535," in Forum In Research, Science, and Technology (FIRST), Palembang, 2015.

[8] Artanto and Dian, "Interaksi Arduino dan LabVIEW," 2012.

[9] Datasheet, "8 bit AVR Microcontroller with 4/8/16/32K Bytes IN System Programmable Flash ATma48PA, Atmega88PA, ATmega168PA, and ATmega328P, ATMEL," 2019.

[10] Kurniawan and Dayat, "ATMega 8 dan Aplikasinya. PT Elex Media Komputindo," 2019. 